Rev. Bras. Saúde Prod. Anim., Salvador, v.14, n.3, p.426-436 jul./set., 2013 http://www.rbspa.ufba.br ISSN 15199940

\title{
Avaliação de genótipos de milheto para silagem no semiárido
}

\author{
Evaluation of genotypes of pearl millet for silage in semiarid
}

\author{
PINHO, Ricardo Martins Araujo ${ }^{1 *}$; SANTOS, Edson Mauro ${ }^{1}$; RODRIGUES, José \\ Avelino Santos ${ }^{2}$; MACEDO, Carlos Henrique Oliveira ${ }^{1}$; CAMPOS, Fleming Sena ${ }^{3}$; \\ RAMOS, João Paulo de Farias ${ }^{1}$; BEZERRA, Higor Fábio Carvalho ${ }^{1}$; PERAZZO, \\ Alexandre Fernandes ${ }^{3}$
}

\author{
${ }^{1}$ Universidade Federal da Paraíba, Centro de Ciências Agrárias, Programa de Pós-graduação em \\ Zootecnia, Areia, Paraíba, Brasil. \\ ${ }^{2}$ Embrapa Milho e Sorgo, Sete Lagoas, Minas Gerais, Brasil. \\ ${ }^{3}$ Universidade Federal da Bahia, Escola de Medicina Veterinária e Zootecnia, Programa de Pós- \\ Graduação em Zootecnia, Salvador, Bahia, Brasil. \\ *Endereço para correspondência: ricardo-zootec@hotmail.com
}

\section{RESUMO}

Objetivou-se com esta pesquisa avaliar o rendimento forrageiro, as características agronômicas e morfométricas das plantas e as perdas, perfil fermentativo e composição bromatológica de silagens de genótipos de milheto. Para avaliação das características agronômicas e morfométricas dos genótipos utilizou-se o delineamento experimental em blocos casualizados, com cinco repetições. $\mathrm{Na}$ fase de avaliação dos silos experimentais o delineamento passou a ser inteiramente casualizado, com quatro repetições. Foram testados os cultivares Sauna B, CMS 01, ADR 500, BRS 1501 e CMS 03. Não houve diferença para a PMV, PMS e MS. Os genótipos de milheto apresentaram uma média de PMV de $9.073 \mathrm{~kg} / \mathrm{ha}$ no primeiro ciclo e de $10.054 \mathrm{~kg} / \mathrm{ha}$ na rebrota. Quanto à lâmina foliar e a produção de colmo não houve diferença em ambos os cortes. Os teores médios de AL variaram de 1,98 a $5,17 \%$, para os genótipos SAUNA B e CMS 01, respectivamente. Para os teores de PB verificou-se efeito significativo entre os genótipos estudados, com valores variando de 11,56 a $7,90 \%$. Os genótipos estudados se equivaleram tanto na avaliação das plantas como na avaliação das silagens, podendo ser utilizados como uma alternativa forrageira em regiões semiáridas.

Palavras-chave: ácido lático, colmo, ensilagem, Pennisetum glaucum, proteína bruta

\section{SUMMARY}

The objective of this research was to evaluate the forage yield, agronomic characteristics and morphometric plants and losses, fermentation and chemical composition of silages of pearl millet genotypes. To evaluate the agronomic and morphometric characteristics of genotypes it was used the randomized blocks experimental design with five replicates. In the phase of silos evaluation the design has become completely randomized design with four replications. Cultivars tested were Sauna B, CMS 01, ADR 500, BRS 1501 and CMS 03. There was no difference for PFF, DMP and DM. The pearl millet genotypes had a average PMV of 9073 $\mathrm{kg} / \mathrm{ha}$ in the first cycle and $10.054 \mathrm{~kg} / \mathrm{ha}$ in the regrowth. As to the leaf and stem production there was not difference in both cuts. The concentration of AL ranged from 1.98 to $5.17 \%$ for genotypes $\mathrm{B}$ and CMS SAUNA 01, respectively. For the crude protein there was a significant effect among genotypes studied, with values ranging from 11.56 to $7.90 \%$. The genotypes studied were equivalent in both the evaluation of the plants and the evaluation of silage, which can be used as an alternative fodder in semiarid regions.

Keywords: crude protein, ensilage, lactic acid, Pennisetum glaucum, stem 


\section{INTRODUÇ̃̃̃O}

O Semiárido nordestino caracteriza-se pela ocorrência de chuvas mal distribuídas e imprevisíveis, comprometendo o crescimento e o desenvolvimento dos animais devido à escassez e o baixo valor nutritivo das forrageiras no período seco do ano. Para reduzir os impactos da estacionalidade na produção de forragens é necessário que o excedente de forragem no período chuvoso seja conservado e utilizado no período de escassez.

A utilização de volumosos conservados na forma de silagem tem sido uma eficiente solução nos períodos de escassez de alimentos, onde se tem uma baixa produção de forragens, proporcionando um volumoso de boa qualidade e largamente utilizado na alimentação animal (POSSENTI et al., 2005).

O milheto é uma alternativa para a produção de forragem no semiárido por ser uma gramínea de origem tropical, de fácil instalação e manejo, ciclo curto, elevado valor nutritivo e adaptado a diferentes condições de clima e solo, além de apresentar persistência a altas temperaturas e períodos de déficit hídrico (KOLLET et al., 2006), além de possuir capacidade de rebrota.

Ultimamente, tem-se desenvolvido e lançado novos genótipos de milheto, no entanto, pesquisas são essenciais para a obtenção de respostas agronômicas e de suas silagens, proporcionando a recomendação de cultivares promissores para as suas diversas utilidades nos sistemas de produção agropecuária.

Diante disto, objetivou-se com esta pesquisa avaliar o rendimento forrageiro, as características agronômicas e morfométricas das plantas e as perdas, perfil fermentativo e composição bromatológica de silagens de genótipos de milheto.

\section{MATERIAL E MÉTODOS}

$\mathrm{O}$ experimento foi desenvolvido na Estação Experimental Pendência, da Empresa de Pesquisa Agropecuária da Paraíba S.A (EMEPA), situada na Mesorregião do Agreste paraibano, Microrregião do Curimataú, município de Soledade.

O solo da área experimental apresentou os seguintes atributos químicos (perfil de

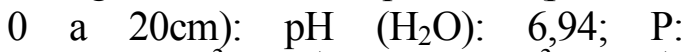
$70,38 \mathrm{mg} / \mathrm{dm}^{3} ; \quad \mathrm{K}^{+}: \quad 82 \mathrm{mg} / \mathrm{dm}^{3} ; \quad \mathrm{Na}^{+}$: $0,37 \mathrm{cmol}_{d} / \mathrm{dm}^{3}: \mathrm{H}^{+}+\mathrm{Al}^{+3}: 2,06 \mathrm{cmol}_{\mathrm{d}} / \mathrm{dm}^{3}$; $\mathrm{Al}^{+3}: 0,0 \mathrm{cmol}_{\mathrm{d}} / \mathrm{dm}^{3} ; \mathrm{Ca}^{+2}: 7,45 \mathrm{cmol}_{\mathrm{d}} / \mathrm{dm}^{3}$; $\mathrm{Mg}^{+2}: \quad 2,40 \mathrm{cmol}_{\mathrm{d}} / \mathrm{dm}^{3} ;$ saturação de bases: $83,0 \%$ e matéria orgânica: $10,55 \mathrm{~g} / \mathrm{kg}$. Com base na análise de solo, não se fez necessário correção de acidez nem adubações fosfatada e potássica.

Para avaliação das características agronômicas e morfométricas dos genótipos utilizou-se o delineamento experimental em blocos casualizados, com cinco repetições. Foram testados os cultivares Sauna B, CMS 01, ADR 500, BRS 1501 e CMS 03. Na fase de avaliação dos silos experimentais, todo o material de cada bloco foi cortado para ensilagem, e as repetições passaram a ser constituídas pelos silos experimentais, de modo que o delineamento passou a ser inteiramente casualizado, com quatro repetições.

$\mathrm{O}$ espaçamento utilizado na cultura foi de $0,5 \mathrm{~m}$ entre linhas. As parcelas apresentaram $1,5 \mathrm{~m}$ de largura por $4,0 \mathrm{~m}$ de comprimento. A semeadura do milheto foi realizada em 04 de março de 2011, em sulcos, a uma profundidade de, aproximadamente, $1,0 \mathrm{~cm}$. Após o desbaste, visou-se obter 15 plantas $/ \mathrm{m}$ linear. A precipitação pluvial ocorrida 
na área experimental durante o primeiro ciclo da cultura foi de $230 \mathrm{~mm}$. A colheita das plantas do primeiro ciclo foi realizada aos 48 dias após a semeadura (DAS). Após 15 dias de implantado, efetuou-se adubação nitrogenada, com $40 \mathrm{~kg}$ de nitrogênio por hectare na forma de sulfato de amônio.

O desenvolvimento da rebrota do milheto teve início 21 de abril de 2011. Durante o período de rebrota houve uma precipitação pluvial de $355 \mathrm{~mm}$. Após 15 dias do início da rebrotação foi feita uma adubação de cobertura com $40 \mathrm{~kg} / \mathrm{ha}$ de nitrogênio, na forma de sulfato de amônio. A colheita das plantas da rebrota foi realizada 42 dias após o primeiro corte

Em ambos os cortes o milheto foi colhido quando os grãos apresentavam-se no estádio leitoso/pastoso. Os cortes das plantas foram realizados manualmente, com auxílio de cutelo, a $10 \mathrm{~cm}$ do solo.

Para a avaliação dos constituintes morfológicos foram selecionadas aleatoriamente duas plantas por unidade experimental e separadas nos constituintes colmo, lâmina foliar e espiga e, em seguida, armazenados em sacos identificados, pesados e acondicionados em estufa de ventilação forçada, durante 72 horas, a temperatura de $65^{\circ} \mathrm{C}$, até atingir peso constante, para se estabelecer a proporção com base na matéria seca.

Já para a avaliação da planta, foram considerados, a produção de dois metros lineares por parcela, um metro de cada linha, utilizando-se as duas linhas centrais. A produção em matéria verde por hectare foi obtida pelo produto entre a produção por metro linear cultivado e o total de metros lineares cultivados por hectare. A produção em matéria seca foi estimada pelo produto entre a produção em massa verde e o teor de matéria seca, sendo, posteriormente, convertida em produção de matéria seca por hectare.

As características morfométricas foram avaliadas em duas plantas por unidade experimental, localizadas na linha central. As variáveis avaliadas foram: altura de plantas e o diâmetro de colmo, sendo medidos com trena e paquímetro digital.

Simultaneamente a separação dos constituintes das plantas, o material restante de cada unidade experimental foi picado em máquina estacionária em partículas de aproximadamente $2 \mathrm{~cm}$, e ensilado em silos de PVC, com $15 \mathrm{~cm}$ de diâmetro e $30 \mathrm{~cm}$ de altura, dotados de válvula de bunsen, para escape dos gases. No fundo dos silos foram colocados $1,5 \mathrm{~kg}$ de areia, para captura do efluente, separado por um tecido de algodão. A compactação do material foi realizada com soquetes de madeira, colocando-se aproximadamente $2 \mathrm{~kg}$ de forragem fresca por silo. Os silos foram abertos 30 dias após a ensilagem.

Decorridos os 30 dias, os silos foram abertos e em seguida, coletados duas amostras de cada unidade experimental para a realização das análises no Laboratório de Nutrição Animal do Centro de Ciências Agrárias da Universidade Federal da Paraíba (UFPB). No momento da abertura dos silos, descartaram-se as porções superior e inferior de cada um, equivalendo a $5 \mathrm{~cm}$ aproximadamente cada. A porção central foi homogeneizada para então se proceder a retirada de uma amostra de aproximadamente $200 \mathrm{~g}$ para determinação de $\mathrm{pH}$, segundo Bolsen et al. (1992) e para análise de ácidos orgânicos seguindo metodologia descrita por Kung jr. \& Ranjit (2001).

No momento da abertura dos silos, foram coletadas amostras de aproximadamente $300 \mathrm{~g}$ foi coletada de cada silo. Estas amostras foram pré-secas em estufa de ventilação forçada a $65^{\circ} \mathrm{C}$ por $72 \mathrm{~h}$ e 
moídas em moinho de facas tipo Willey, para determinação dos constituintes bromatológicos. As determinações de matéria seca (MS), matéria orgânica (MO), matéria mineral (MM), extrato etéreo (EE) e proteína bruta (PB), foram determinadas segundo metodologia descrita por Silva \& Queiroz (2002), fibra em detergente neutro (FDN) foi avaliado utilizando as composições de detergente recomendada por Mertens
(2002). A determinação de carboidratos solúveis (CHOs) foi realizada segundo Deriaz (1961). Foram calculados os teores de carboidratos totais $(\mathrm{CT}=100$ $-(\% \mathrm{~PB}+\% \mathrm{EE}+\% \mathrm{MM})$ e dos carboidratos não-fibrosos $(\mathrm{CNF}=\mathrm{CT}-$ FDNcp), de acordo com Sniffen et al. (1992). Os valores médios da composição bromatológica dos genótipos antes da ensilagem baseados na matéria seca podem ser observados na Tabela 1.

Tabela 1. Composição bromatológica da planta de diferentes genótipos de milheto

\begin{tabular}{lrrrrccrr}
\hline \multirow{2}{*}{ Tratamento } & \multicolumn{1}{c}{ PB } & FDN & EE & MO & CZ & CT & CHO's & CNF \\
\cline { 2 - 8 } & & & & & $\%$ & & & \\
\hline SAUNA B & 10,65 & 65,26 & 2,01 & 83,86 & 16,14 & 71,19 & 9,08 & 5,93 \\
CMS 01 & 9,76 & 64,12 & 2,55 & 83,41 & 16,59 & 71,10 & 8,70 & 6,98 \\
ADR 500 & 8,57 & 62,97 & 1,84 & 86,38 & 13,61 & 75,98 & 7,18 & 13,00 \\
BRS 1501 & 10,82 & 66,66 & 1,42 & 83,43 & 16,57 & 71,19 & 6,99 & 4,52 \\
CMS 03 & 8,36 & 65,39 & 4,34 & 86,49 & 13,51 & 73,79 & 7,30 & 8,39 \\
\hline
\end{tabular}

$\mathrm{PB}=$ proteína bruta, $\mathrm{FDN}=$ fibra em detergente neutro, $\mathrm{EE}=$ extrato etéreo, $\mathrm{MO}=$ matéria orgânica, $\mathrm{CZ}=$ cinzas, $\mathrm{CT}=$ carboidratos totais, $\mathrm{CHO}$ 's $=$ carboidratos solúveis, e $\mathrm{CNF}=$ carboidratos não-fibrosos.

As perdas de matéria seca nas silagens sob as formas de gases e efluentes foram quantificadas por diferença de peso. As perdas por gases (PG), efluentes (PE) e a recuperação da matéria seca (RMS) foram obtidas segundo equações descritas por Zanine et al. (2010).

Os resultados obtidos foram submetidos à análise de variância e os valores médios foram comparados pelo teste de Scott Knott, ao nível de $5 \%$ de probabilidade, usando-se o programa SISVAR (FERREIRA, 2008).

\section{RESULTADOS E DISCUSSÃO}

Os resultados para a produtividade de matéria verde (PMV) e matéria seca (PMS), teor de matéria seca (MS), altura de planta (AP) e diâmetro de colmo (DC) dos cinco genótipos do milheto estão apresentadas na Tabela 2. Não houve diferença $(\mathrm{P}>0,05)$ para a PMV, PMS e MS, no entanto o genótipo CMS 03 apresentou valores superiores em relação a estas variáveis, obtendo-se uma PMS de 2,62Mg/ha. Com relação à PMV e PMS, apesar da discrepância entre as produções observadas nos cortes 1 e 2, a não significância pode estar associada aos elevados coeficiente de variação. Esses resultados são inferiores aos encontrados por Kollet et al. (2006), que estudando genótipos de milheto encontraram média de, aproximadamente, $6,0 \mathrm{Mg}$ de $\mathrm{MS} / \mathrm{ha}$ colhidos aos 49 dias após semeio. Essa PMS inferior encontrada nesta pesquisa pode ser explicada, pelo acontecimento de várias chuvas consecutivas que resultou em alagamento da área, o que pode ter comprometido o desenvolvimento da cultura. 
Bonfim-Silva et al. (2011) avaliando desenvolvimento inicial de gramíneas submetidas ao estresse hídrico, comprovaram que o milheto é sensível a condições de alagamento, acarretando em uma maior queda de número de folhas, massa seca de folha e altura.

Tabela 2. Valores médios de teor de matéria seca (MS), produção de matéria verde (PMV), produção de matéria seca (PMS), altura de planta (AP) e diâmetro de colmo (DC) dos genótipos de milheto, em condições de primeiro e segundo corte

\begin{tabular}{|c|c|c|c|c|c|c|c|c|c|c|}
\hline \multirow{3}{*}{ Genótipos } & \multicolumn{2}{|c|}{$\begin{array}{l}\text { MS } \\
(\%)\end{array}$} & \multicolumn{2}{|c|}{$\begin{array}{c}\text { PMV } \\
(\mathrm{Mg} / \mathrm{ha})\end{array}$} & \multicolumn{2}{|c|}{$\begin{array}{c}\text { PMS } \\
(\mathrm{Mg} / \mathrm{ha})\end{array}$} & \multicolumn{2}{|c|}{$\begin{array}{l}\mathrm{AP} \\
(\mathrm{cm})\end{array}$} & \multicolumn{2}{|c|}{$\begin{array}{l}\mathrm{DC} \\
(\mathrm{cm})\end{array}$} \\
\hline & Corte & Corte & Corte & Corte & Corte & Corte & Corte & Corte & Corte & Corte \\
\hline & 1 & 2 & 1 & 2 & 1 & 2 & 1 & 2 & 1 & 2 \\
\hline Sauna B & 17,95 & 25,41 & 5,97 & 7,52 & 1,08 & 2,41 & $60^{\mathrm{b}}$ & $123^{a}$ & $0,52^{\mathrm{a}}$ & $0,94^{\mathrm{a}}$ \\
\hline CMS 01 & 18,56 & 29,80 & 8,66 & 8,90 & 1,95 & 2,90 & $67^{\mathrm{b}}$ & $134^{\mathrm{a}}$ & $0,45^{\mathrm{b}}$ & $0,73^{\mathrm{b}}$ \\
\hline ADR 500 & 21,45 & 30,57 & 9,50 & 10,77 & 2,32 & 2,95 & $90^{\mathrm{a}}$ & $128^{\mathrm{a}}$ & $0,36^{\mathrm{c}}$ & $0,59^{\mathrm{b}}$ \\
\hline BRS 1501 & 22,35 & 31,25 & 11,94 & 11,21 & 2,41 & 3,25 & $79^{\mathrm{b}}$ & $120^{\mathrm{a}}$ & $0,34^{\mathrm{c}}$ & $0,67^{\mathrm{b}}$ \\
\hline CMS 03 & 22,73 & 33,01 & 12,41 & 11,85 & 2,62 & 3,41 & $102^{\mathrm{a}}$ & $141^{\mathrm{a}}$ & $0,40^{\mathrm{c}}$ & $0,80^{\mathrm{a}}$ \\
\hline CV (\%) & 19,28 & 21,22 & 51,95 & 52,62 & 65,73 & 54,33 & 26,6 & 17,79 & 11,92 & 19,44 \\
\hline
\end{tabular}

Médias seguidas de letras diferentes na coluna diferem entre si pelo teste de Scott-Knott, ao nível de 5\% de significância.

$\mathrm{CV}=$ coeficiente de variação.

Para critério de comparação, na rebrota os genótipos estudados nesta pesquisa apresentaram resultados superiores aos observados na pesquisa de Kollet et al. (2006). As produções encontradas para PMS variaram de $2,4 \mathrm{Mg} /$ ha para o genótipo Sauna B a $3,414 \mathrm{Mg} /$ ha para o CMS 03. Em todos os materiais a rebrota obteve resultados de teor de matéria seca próximo ou acima de $30 \%$. A adubação nitrogenada de cobertura associada com quantidades adequadas de umidade no solo pode ter contribuído para uma rebrota mais vigorosa $\mathrm{e}$ produtiva, ao passo que as condições de chuvas torrenciais e em quantidade elevadas observadas no primeiro corte, podem ter reduzido a eficiência da adubação, aumentando as perdas por lixiviação ou nitrificação no nitrogênio. Os genótipos de milheto apresentaram uma média de PMV de $9,073 \mathrm{Mg} /$ ha no primeiro ciclo e de $10,054 \mathrm{Mg} /$ ha na rebrota. Quanto aos valores da rebrota, os resultados foram superiores aos encontrados por Guimarães Júnior et al. (2009), que estudando genótipos de milheto, encontraram PMV média de $6,460 \mathrm{Mg} / \mathrm{ha}$. Vale ressaltar o potencial de rebrota do milheto, a despeito do comprometimento do desenvolvimento no primeiro ciclo, sendo essa uma característica favorável para incrementar o aporte forrageiro.

Com relação à altura de planta houve diferença $(\mathrm{P}<0,05)$ no primeiro corte, não havendo efeito no segundo corte. No primeiro corte os genótipos ADR 500 e CMS 03 foram superiores as demais, com AP de 90 e $102 \mathrm{~cm}$, respectivamente. No segundo corte, apesar de não ter havido diferença estatística entre os cortes, todos os genótipos apresentaram AP superiores quando comparados com a AP do primeiro corte, demonstrando que no segundo ciclo as plantas tiveram um ambiente melhor para seu 
desenvolvimento, não havendo neste caso problemas com alagamento.

Quanto ao diâmetro de colmo (DC) houve diferença $(\mathrm{P}<0,05)$ em ambos os cortes. No primeiro corte o genótipo SAUNA B se destacou entre os demais e no segundo corte se destacaram os genótipos SAUNA B e CMS 03. Quanto ao DC o mesmo ocorrido com a AP, foi observado quando as plantas foram avaliadas no segundo corte, nas quais os genótipos apresentaram resultados superiores quando comparados ao corte anterior.

Pode se observar que nos genótipos de milheto estudados, a lâmina foliar não apresentou grupos distintos $(\mathrm{P}>0,05)$, para ambos os cortes, obtendo-se uma média de $22,21 \%$ no primeiro corte e de $15 \%$ no segundo corte (Tabela 3 ), essa não diferenciação pode está associada aos elevados coeficientes de variação. Esses resultados se diferenciam dos observados por Kollet et al. (2006), principalmente na inversão das proporções no primeiro e segundo corte, observando que nesta pesquisa os percentuais de lâmina no segundo corte foram superiores aos do primeiro, o inverso acontecendo no trabalho citado anteriormente.

Tabela 3. Valores médios dos percentuais de lâmina foliar, colmo e espiga dos genótipos de milheto, em condições de primeiro e segundo corte

\begin{tabular}{lrccccc}
\hline \multirow{2}{*}{ Genótipos } & \multicolumn{2}{c}{ Lamina foliar (\%) } & \multicolumn{2}{c}{ Colmo (\%) } & \multicolumn{2}{c}{ Espiga (\%) } \\
\cline { 2 - 7 } & Corte 1 & Corte 2 & Corte 1 & Corte 2 & Corte 1 & Corte 2 \\
\hline Sauna B & 23,76 & 12,25 & 72,23 & 61,84 & $4,00 \mathrm{~b}$ & 25,90 \\
CMS 01 & 33,33 & 13,62 & 59,55 & 65,03 & $7,11 \mathrm{~b}$ & 21,35 \\
ADR 500 & 15,26 & 16,50 & 64,40 & 61,44 & $20,32 \mathrm{a}$ & 22,05 \\
BRS 1501 & 20,54 & 17,374 & 57,33 & 61,41 & $24,50 \mathrm{a}$ & 21,214 \\
CMS 03 & 18,16 & 15,038 & 50,30 & 68,38 & $29,15 \mathrm{a}$ & 16,576 \\
\hline CV (\%) & 54,23 & 36,13 & 23,35 & 14,66 & 59,45 & 23,53 \\
\hline
\end{tabular}

Médias seguidas de letras diferentes na coluna diferem entre si pelo teste de Scott-Knott, ao nível de 5\% de significância.

$\mathrm{CV}=$ coeficiente de variação.

A produção de espiga no primeiro corte diferenciou-se em dois grupos $(\mathrm{P}<0,05)$, com destaque para o ADR 500, BRS 1501 e CMS 03, que obtiveram uma média de $24,66 \%$, enquanto os outros genótipos obtiveram $5,55 \%$, sendo uma diferença considerável (Tabela 3). Com algumas variedades observou-se que a produção de espiga foi maior que a lâmina foliar, o que pode ter ocorrido por uma aceleração no seu ciclo fenológico, devido à elevada precipitação durante o período do experimento.
$\mathrm{Na}$ produção de colmo não houve diferença $(\mathrm{P}>0,05)$ entre os cortes, apresentando uma média de $60,76 \%$ no primeiro corte e de $63,6 \%$ no segundo (Tabela 3). Scheffer-Basso et al. (2004) comprovaram em seus estudos que o aumento do acúmulo da fitomassa agrupam-se na proporção de colmo, seguido pela lâmina foliar e finalizando com a proporção de espiga, isso ocorre em condições climáticas adequadas, como na relação pluviométrica e na temperatura do ambiente. A proporção de colmo no primeiro ciclo é inferior 
aos encontrados por Kollet et al. (2006), porém no segundo corte os resultados encontrados por esses autores foi bastante inferior, que estudando genótipos de milheto em diferentes alturas, observou percentual de colmo médio de $75 \%$ e de $33 \%$ no primeiro e segundo corte, respectivamente, colhidos aos 49 dias após o semeio. O percentual de colmo no segundo corte é explicado considerando que a planta teve um bom crescimento na rebrota, devido às condições já comentadas.
Não houve efeito $(\mathrm{P}>0,05)$ nas variáveis perdas por gases (PG), recuperação de matéria seca (RMS) e perdas por efluentes (PE). Embora não estatisticamente, o genótipo SAUNA B apresentou o menor percentual de PG, proporcionando assim uma maior RMS (Tabela 4). Conforme Santos et al. (2008), quando as silagens apresentam menores valores de perdas por gases, demonstram maior recuperação de matéria seca.

Tabela 4. Valores médios das perdas e do perfil fermentativo de silagens de genótipos de milheto

\begin{tabular}{lcccrrr}
\hline \multirow{2}{*}{ Item } & \multicolumn{5}{c}{ Genótipos } & \multirow{2}{*}{ CV (\%) } \\
\cline { 2 - 5 } & SAUNA B & CMS 01 & ADR 500 & BRS 1501 & CMS 03 & \\
\hline RMS (\%) & 91,07 & 83,86 & 84,61 & 94,05 & 86,67 & 6,16 \\
PG (\%) & 4,63 & 4,69 & 7,28 & 5,68 & 7,38 & 27,16 \\
PE (kg/Mg) & 33,05 & 32,75 & 58,18 & 33,64 & 34,22 & 42,64 \\
pH & $3,17^{\mathrm{b}}$ & $3,17^{\mathrm{b}}$ & $3,19^{\mathrm{b}}$ & $3,27^{\mathrm{b}}$ & $3,56^{\mathrm{a}}$ & 2,97 \\
AL (\%) & $1,98^{\mathrm{c}}$ & $3,52^{\mathrm{b}}$ & $4,80^{\mathrm{a}}$ & $5,32^{\mathrm{a}}$ & $5,39^{\mathrm{a}}$ & 15,94 \\
AA (\%) & $0,55^{\mathrm{b}}$ & $0,75^{\mathrm{ab}}$ & $0,75^{\mathrm{ab}}$ & $0,76^{\mathrm{ab}}$ & 0,92 & 15,35 \\
AB (\%) & $0,024^{\mathrm{b}}$ & $0,028^{\mathrm{ab}}$ & $0,030^{\mathrm{a}}$ & $0,030^{\mathrm{a}}$ & $0,030^{\mathrm{a}}$ & 11,13 \\
AP (\%) & 0,12 & 0,15 & 0,1 & 0,16 & 0,16 & 15,35 \\
\hline
\end{tabular}

Médias seguidas de letras diferentes na coluna diferem entre si pelo teste de Scott-Knott, ao nível de 5\% de significância .

RMS $=$ recuperação de matéria seca, $\mathrm{PG}=$ perdas por gases, $\mathrm{PE}=$ perdas por efluentes, $\mathrm{AL}=$ ácido lático, $\mathrm{AA}=$ ácido acético, $\mathrm{AB}=$ ácido butírico, $\mathrm{AP}=$ ácido propiônico.

$\mathrm{CV}=$ coeficiente de variação.

A formação de gás na silagem é resultante de fermentações secundárias, que normalmente cresce em meios com pH mais elevado. Os baixos valores de PG demonstram que no processo de ensilagem houve pouca participação da fermentação por enterobactérias, o que resultou na diminuição das fermentações secundárias. Esses resultados podem ser explicados pela baixa concentração de ácido acético (Tabela 4), que é um produto da fermentação das enterobactérias. A redução do $\mathrm{pH}$ das silagens pode ter inibido o crescimento de populações de enterobactérias e bactérias clostrídicas, que são produtoras dos ácidos acético e butírico, reduzindo sua concentração na silagem (SANTOS et al., 2008).

As perdas por efluente foram semelhantes para os genótipos e dentro da faixa encontrada para as gramíneas de clima tropical, e podem ter colaborado para as perdas de matéria seca, tendo em vista que as perdas por gases foram baixas (Tabela 4). Ribeiro et al. (2009), observaram que quanto maior o teor de MS menor será a produção de efluente, pois disponibilizam substratos fermentáveis 
aos microrganismos, por causa da maior capacidade fermentativa e da digestibilidade das silagens.

Os teores médios de $\mathrm{AL}$ variaram $(\mathrm{P}<0,05)$ de 1,98 (Sauna B) a $5,17 \%$ (média dos genótipos ADR 500, BRS 1501 e CMS 03). A variedade CMS 1 apresentou valor intermediário $(3,52 \%)$ (Tabela 4). Estes resultados sugerem que as plantas com maior percentual de AL apresentaram melhores condições para o desenvolvimento de bactérias láticas, ou seja, os genótipos citados apresentaram uma relação adequada de CHO's e de MS, que são atributos necessários para uma boa fermentação. Guimarães Júnior et al. (2005), trabalhando com os genótipos CMS 01, BRS 1501 e BN-2, observaram teor médio de 5,86\% de AL aos 28 dias de fermentação.

Os teores de AA variaram $(\mathrm{P}<0,05)$ de 0,55 a $0,92 \%$, respectivamente para as variedades Sauna B e CMS 03 (Tabela 4). No entanto, todas as variedades apresentaram média de $0,75 \%$. Concentrações baixas de AA como as observada neste estudo, demonstram que houve pouca incidência de fermentações por enterobactérias, que são produtoras deste ácido.

$\mathrm{O}$ percentual de $\mathrm{AB}$ também variou significativamente entre os genótipos, apresentando as plantas ADR 500; BRS 1501 e CMS 03 a maior média $(0,030 \%)$ de $\mathrm{AB}$ na silagem aos 30 dias de fermentação (Tabela 4). O genótipo Sauna B apresentou a menor média $(0,0240 \%)$. Tendo em vista que os clostrídios afetam negativamente a qualidade da silagem e, consequentemente, o consumo dos animais, as concentrações baixas de ácido butírico observadas, demonstram que atividade clostridiana ao longo do processo fermentativo foi insuficiente para gerar perdas consideráveis.

Os teores de AP não variaram $(\mathrm{P}>0,05)$ entre os genótipos com média de $0,15 \%$, no entanto, com relação ao $\mathrm{pH}$ houve diferença $(\mathrm{P}<0,05)$, em que o genótipo CMS 03 foi superior aos demais $(3,56)$, os demais, apresentaram valor médio de 3,27 . Esses resultados são inferiores aos encontrados por Amaral et al. (2008), que trabalhando com as cultivares (BRS 1501; BN 1 e Comum) encontraram valor médio de 3,77 aos 50 dias de ensilagem. Os valores de $\mathrm{pH}$ abaixo da faixa ideal, pode ser explicado pela elevada quantidade de carboidratos solúveis (Tabela 1) presentes nos genótipos, uma vez que são o principal substrato para bactérias láticas produzirem ácido lático, reduzindo o $\mathrm{pH}$ do meio.

Para os valores de FDN, MO e MM, os valores são semelhantes aos encontrados na composição da planta in natura (Tabela 1), demonstrando que houve pouca degradação destes componentes no processo de ensilagem (Tabela 5).

Para os teores de PB verificou-se efeito significativo $\quad(\mathrm{P}<0,05) \quad$ entre os genótipos estudados, com valores superiores variando de $(11,56 ; 11,01 \mathrm{e}$ 10,94) para os genótipos SAUNA B, BRS 1501, CMS 01 respectivamente (Tabela 5). Esses valores podem ser explicados pela elevada proporção de folhas obtidas nestes genótipos, o que resultou em considerável teor de $\mathrm{PB}$, já que as folhas, principalmente jovens, possuem elevada quantidade deste componente em sua constituição. Como estes genótipos no primeiro corte não tiveram um desenvolvimento expressivo houve uma concentração do nitrogênio absorvido, que associado à aceleração do ciclo e uma menor altura de plantas, resultaram nesses teores de PB observados.

Para os CT houve efeito significativo $(\mathrm{P}<0,05)$ sendo o genótipo ADR 500 com maior percentual $69,24 \%$, fato 
Rev. Bras. Saúde Prod. Anim., Salvador, v.14, n.3, p.426-436 jul./set., 2013 http://www.rbspa.ufba.br ISSN 15199940

associado com os maiores teores de FDN e menores percentuais de PB encontrado correspondente a esse genótipo conforme demonstrado na Tabela 1. Com relação aos CT, houve uma adequada diminuição deste componente da planta em relação à da silagem, devido ao consumo de carboidratos solúveis no processo de ensilagem.

Tabela 5. Valores médios da composição bromatológica de silagens de genótipos de milheto

\begin{tabular}{lrrrrrrr}
\hline \multirow{2}{*}{ Cultivar } & MS & PB & EE & FDN & MO & MM & CT \\
\cline { 2 - 7 } & \multicolumn{7}{c}{$\%$} \\
\hline SAUNA B & $18,22^{\mathrm{a}}$ & $11,56^{\mathrm{a}}$ & $5,45^{\mathrm{a}}$ & $65,56^{\mathrm{a}}$ & $82,31^{\mathrm{a}}$ & $17,68^{\mathrm{a}}$ & $65,30^{\mathrm{b}}$ \\
CMS 01 & $18,35^{\mathrm{a}}$ & $10,94^{\mathrm{a}}$ & $5,16^{\mathrm{a}}$ & $66,80^{\mathrm{a}}$ & $81,44^{\mathrm{a}}$ & $18,56^{\mathrm{a}}$ & $65,34^{\mathrm{b}}$ \\
ADR 500 & $17,82^{\mathrm{a}}$ & $8,71^{\mathrm{b}}$ & $5,30^{\mathrm{a}}$ & $69,41^{\mathrm{a}}$ & $83,26^{\mathrm{a}}$ & $16,73^{\mathrm{a}}$ & $69,24^{\mathrm{a}}$ \\
BRS 1501 & $18,53^{\mathrm{a}}$ & $11,01^{\mathrm{a}}$ & $6,00^{\mathrm{a}}$ & $63,48^{\mathrm{a}}$ & $82,13^{\mathrm{a}}$ & $17,87^{\mathrm{a}}$ & $65,12^{\mathrm{b}}$ \\
CMS 03 & $18,92^{\mathrm{a}}$ & $7,90^{\mathrm{b}}$ & $5,42^{\mathrm{a}}$ & $64,56^{\mathrm{a}}$ & $80,14^{\mathrm{a}}$ & $19,85^{\mathrm{a}}$ & $66,82^{\mathrm{b}}$ \\
\hline CV $^{8}(\%)$ & 4,90 & 5,89 & 12,58 & 5,11 & 2,61 & 11,77 & 3,33 \\
\hline
\end{tabular}

Média seguidas de mesma letra na linha não diferem entre si pelo teste de Scott-Knott, ao nível de 5\% de significância.

$\mathrm{MS}=$ matéria Seca, $\mathrm{PB}=$ proteína bruta, $\mathrm{EE}=$ extrato etéreo, $\mathrm{FDN}=$ fibra em detergente neutro, $\mathrm{MO}=$ matéria orgânica, $\mathrm{MM}=$ matéria mineral, $\mathrm{CT}=$ carboidratos totais.

$\mathrm{CV}=$ coeficiente de variação.

Apesar do desenvolvimento dos genótipos terem sido comprometidos pelas condições de chuvas torrenciais e em quantidades elevadas no primeiro ciclo, no entanto os genótipos tiveram um desenvolvimento compensatório na rebrota, apresentando características superiores quando comparadas com o primeiro ciclo. Quanto aos valores relacionados às perdas, perfil fermentativo e composição bromatológica os genótipos apresentaram características fermentativas e de valor nutritivo relevantes, mesmo tendo o seu desenvolvimento comprometido pelas condições de alagamento.

Os genótipos estudados se equivaleram tanto na avaliação das plantas como na avaliação das silagens, podendo ser utilizados como uma alternativa forrageira para produção de volumoso suplementar para regiões com estacionalidade climática.

\section{REFERÊNCIAS}

AMARAL, P.N.C.; EVANGELISTA, A.R.; SALVADOR, F.M.; PINTO, J.C. Qualidade e valor nutritivo da silagem de três cultivares de milheto. Ciência e Agrotecnologia, v.32, n.2, p. 611-617, 2008.

BOLSEN, K.K., LIN, C., BRENT, C. R.; FEYERHERM, A. M.; URBAN, J. E.; AIMUTIS, W. R. Effect of silage additives on the microbial succession and fermentation process of alfalfa and corn silages. Journal of Dairy Science, v.75, n.11, p.3066-83, 1992.

BONFIM-SILVA, E.M.; SILVA, T.J.A.; CABRAL, C.E.A.; KROTH, B.E.; REZENDE, D. Desenvolvimento inicial de gramíneas submetidas ao estresse hídrico. Revista Caatinga, v.24, n.2, p.180-186, 2011. 
DERIAZ, R. E. Routine analysis of carbohydrate and lignin in herbage.

Journal of Science Food and Agriculture, v.12, p.150-160, 1961.

FERREIRA, D.F. SISVAR: Um programa para análises e ensino de estatística. Revista Symposium, v.6, p.36-41, 2008.

GUIMARÃES JÚNIOR, R.; GONÇALVES, L.C.; RODRIGUES, J.A.S.; JAYME, D. G.; PIRES, D. A. A.; BORGES, A. L. C. C.; RODRIGUEZ, N. M.; SALIBA, E. O. S.; BORGES, I. Matéria seca, proteína bruta, nitrogênio amoniacal e $\mathrm{pH}$ das silagens de três genótipos de milheto [Pennisetum glaucum (1). R. Br.] em diferentes períodos de fermentação. Revista Brasileira de Milho e Sorgo, v.4, n.2, p.251-258, 2005.

GUIMARÃES JÚNIOR, R.; GONÇALVES, L.C.; RODRIGUES, J.A.S.; PIRES, D. A. A.; JAYME, D. G.; RODRIGUEZ, N. M.; SALIBA, E. O. S. Avaliação agronômica de genótipos de milheto (Pennisetum glaucum (L). R. Br) plantados em período de safrinha. Archivos de Zootecnia, v.58, p.629-632, 2009.

KOLLET, J.L.; DIOGO, J.M.S.; LEITE, G.G. Rendimento forrageiro e composição bromatológica de variedades de milheto (Pennisetum glaucum (1). R. Br.). Revista Brasileira de Zootecnia, v.35, n.4, p.1308-1315, 2006.

KUNG JUNIOR, L.; RANJIT, N.K. The effect of Lactobacillus buchneri and other additives on the fermentation and aerobic stability of barley silage.

Journal of Dairy Science, v.84, p.1149-1155, 2001.
MERTENS, D.R. Gravimetric determination of amylase teated neutral detergent fiber in feeds with refluxing in beaker or crucibles: collaborative study. Journal of AOAC International, v.85, p1217-1240, 2002.

POSSENTI, R.A.; FERRARI JUNIOR. E.; BUENO, M.S.; BIANCHINI, D.; LEINZ, F.F.; RODRIGUES, C.F. Parâmetros bromatológicos e fermentativos de silagens de milho e girassol. Ciência Rural, v.35, n.5, p.1185-1189, 2005.

RIBEIRO, J.L.; NUSSIO, L.G.; MOURÃO, G.B.; QUEIROZ, O.C.M.; SANTOS, M.C.; SCHIMIDT, P. Efeitos de absorventes de umidade e de aditivos químicos e microbianos sobre o valor nutritivo, o perfil fermentativo e as perdas em silagens de capim-marandu. Revista Brasileira de Zootecnia, v.38, n.2, p.230-239, 2009.

SANTOS, E.M.; ZANINE, A.M.; DANTAS, P.A.S.; DÓREA, J.R.R.; SILVA, T.C.; PEREIRA, O.G.; LANA, R.P.; COSTA, R.G. Composição bromatológica, perdas e perfil fermentativo de silagens de capimelefante com níveis de inclusão de jaca.

Revista Brasileira de Saúde e Produção Animal [online], v.9, n.1, p.64-73, 2008.

SCHEFFER-BASSO, S.M.;

AGRANIONIK, H.; FONTANELI, R.S. Acúmulo de biomassa e composição bromatológica de milheto das cultivares comum e africano. Revista Brasileira de Agrociência, v.10, n.4, p.483-486, 2004.

SILVA, D.J.; QUEIROZ, A.C. Análises de alimentos: métodos químicos e biológicos. 3.ed. Viçosa, MG: Universidade Federal de Viçosa, 2002. $235 p$. 
SNIFFEN, C.J.; O'CONNOR, D.J.; Van SOEST, P.J.; FOX, D.G.; RUSSELL, J.B. A net carbohydrate and protein system for evaluating cattle diets: carbohydrate and protein availability.

Journal of Animal Science, v.70, n.12, p.3562-3577, 1992.

ZANINE, A.M.; SANTOS, E.M.;

DÓREA, J.R.R.; DANTAS, P.A.S.; SILVA, T.C.; PEREIRA, O.G.

Evaluation of elephant grass silage with the addition of cassava scrapings.

Revista Brasileira de Zootecnia, v.39, n.12, p.2611-2616, 2010.

Data de recebimento: 07/03/2013

Data de aprovação: 17/09/2013 